\title{
Pulsatile and Sexually Dimorphic Secretion of Luteinizing Hormone in the Human Infant on the Day of Birth
}

\author{
FRANCIS DE ZEGHER, HUGO DEVLIEGER, AND JOHANNES D. VELDHUIS \\ Department of Pediatrics, University of Leuven Medical School and University Hospital Gasthuisberg, \\ Leuven, Belgium [F.d.Z., H.D.J; and Department of Internal Medicine, University of Virginia Medical School, \\ Charlottesville, Virginia 22908 [J.D.V.]
}

\begin{abstract}
Experimental evidence indicates that the hypothalamic-pituitary-gonadal axis is operational and sexually dimorphic in the mammalian fetus and newborn. We examined the dynamics of human luteinizing hormone (LH) secretion in five male and three female infants on the day of birth, after 34-41 wk of gestation. The infants were polycythemic, and blood samples were obtained every 20 min for 160 to $360 \mathrm{~min}$ during a therapeutic, standardized, isovolumetric, partial exchange transfusion. Serum $\mathbf{L H}$ was measured by an immunoradiometric assay that does not cross-react with human chorionic gonadotropin. The serum profiles of LH presented a striking sex dimorphism with elevated LH levels in male compared with female newborns. Deconvolution analysis of all male LH profiles was consistent with a high-frequency, pulsatile secretory pattern. Testosterone, measured in a pooled serum sample of each infant, was 10-fold higher in male than in female newborns. These results document pulsatile and sexually dimorphic secretion of LH in the human infant as early as the first day of postnatal life. It is possible that the augmented LH secretion in the male newborn participates in the neonatal rise of the serum testosterone concentration. (Pediatr Res 32: 605-607, 1992)
\end{abstract}

\section{Abbreviations}

FSH, follicle-stimulating hormone LH, luteinizing hormone

The hypothalamic-pituitary gonadotropin-gonadal axis is crucial for mammalian reproduction. Experimental evidence obtained in several species suggests that this axis is also functional during fetal and neonatal life (reviewed in 1). Cross-sectional studies of plasma gonadotropin and sex steroid concentrations in human fetuses and newborns have extended support for this concept to the human species $(2,3)$. However, there are at present no data on the dynamics of pituitary gonadotropin secretion in the human before the age of $6 \mathrm{wk}(4)$. We have developed a technically and ethically acceptable model to perform endocrine secretory studies in polycythemic human newborns. Here, we report that the secretion of $\mathrm{LH}$ is already pulsatile and sexually dimorphic on the day of birth.

\section{SUBJECTS AND METHODS}

Five male and three female newborns were studied. All infants had been admitted to the neonatal unit because of symptoms

Received for rapid publication June 12, 1992; accepted August 13, 1992.

Correspondence and reprint requests: Francis de Zegher, Department of Pediatrics, University Hospital Gasthuisberg, 3000 Leuven, Belgium. presumed to be related to polycythemia: acrocyanosis, tachypnea, feeding difficulties, and lethargy. None of the newborns was in severe distress. The median venous hematocrit was 0.72 (range $0.65-0.75$ ). Clinical data of the infants are summarized in Table 1. The decision to perform a therapeutic partial exchange transfusion was made in each case by the attending neonatologist.

During the standardized partial exchange transfusion, blood samples $(1 \mathrm{~mL} / \mathrm{kg})$ were obtained every $20 \mathrm{~min}$ through an umbilical or peripheral arterial catheter. To maintain the intravascular compartment isovolumetric, an isotonic plasma protein solution was administered at a constant rate of $3 \mathrm{~mL} / \mathrm{kg} / \mathrm{h}$. During the procedure, the infants also received a continuous glucose $10 \%$ perfusion $(2.5 \mathrm{~mL} / \mathrm{kg} / \mathrm{h})$ and were not fed. The duration of the sampling for LH determinations varied between 160 and $360 \mathrm{~min}$. The blood was collected into glass tubes; after clotting, the blood was centrifuged; the serum was frozen and kept at $-20^{\circ} \mathrm{C}$ until assay.

The serum concentrations of LH and FSH were measured by immunoradiometric assay, using the LHsp-IRMA and FSHIRMA kits (Medgenix, Fleurus, Belgium), as previously described (5). These assays do not cross-react with human chorionic gonadotropin. All LH samples were assessed in a single assay run; the intraassay coefficient of variation was $5.2 \%$; the sensitivity of the assay was $0.9 \mathrm{U} / \mathrm{L}$. Serum testosterone and estradiol were assayed by RIA. Pooled serum samples for testosterone, estradiol, and FSH measurement were assembled with equal amounts of serum collected over the total sampling session of each infant. The LH profiles were evaluated by deconvolution analysis, a technique examining the possibility of pulsatile hormone secretion, taking into account both the secretory episodes and the metabolic clearance of the investigated hormone (6).

\section{RESULTS}

The serum LH profiles of the examined newborns are depicted in Figure 1. There is a striking difference between the observed LH profiles in male and female newborns $(p<0.05$ for mean LH concentrations; Mann-Whitney U test).

Deconvolution analysis of the LH patterns in female newborns was not performed, as virtually all LH values were below the detection limit of our assay. In contrast, deconvolution analysis of the LH profiles from the male newborns revealed that the secretion of $\mathrm{LH}$ was pulsatile in each of these infants (Fig. 2). The median interpulse interval was 78 min (range $70-87$ min for four of five infants; $124 \mathrm{~min}$ in boy 5); the median LH serum half-life was $79 \mathrm{~min}$ (range 60-89 min for four of five infants; $162 \mathrm{~min}$ in boy 3). The half-duration of the calculated LH secretory bursts (i.e. the duration of the computed secretory burst at half-maximal amplitude) averaged $9.4 \mathrm{~min}$ (range 2.5-19.5 min). The median amplitude of (i.e. the maximal rate of secretion attained within) the secretory burst was $0.19 \mathrm{U} / \mathrm{L} / \mathrm{min}$ (range 
Table 1. Clinical data and concentrations of testosterone, estradiol, and FSH in pooled serum samples from five male and three female newborns

\begin{tabular}{ccccccc}
\hline & $\begin{array}{c}\text { Gestational age } \\
(\mathrm{wk})\end{array}$ & $\begin{array}{c}\text { Birth weight } \\
(\mathrm{g})\end{array}$ & $\begin{array}{c}\text { Postnatal age } \\
(\mathrm{h})\end{array}$ & $\begin{array}{c}\text { Testosterone } \\
(\mathrm{ng} / \mathrm{dL}) *\end{array}$ & $\begin{array}{c}\text { Estradiol } \dagger \\
(\mathrm{pg} / \mathrm{mL})\end{array}$ & $\begin{array}{c}\text { FSH } \\
(\mathrm{U} / \mathrm{L}) \dagger\end{array}$ \\
\hline Males & & & & & \\
\\
1
\end{tabular}

* SI unit conversion: $1 \mathrm{ng} / \mathrm{dL}=34.6741 \mathrm{pmol} / \mathrm{L}$.

$\dagger$ SI unit conversion: $1 \mathrm{ng} / \mathrm{dL}=34.7107 \mathrm{pmol} / \mathrm{L}$.
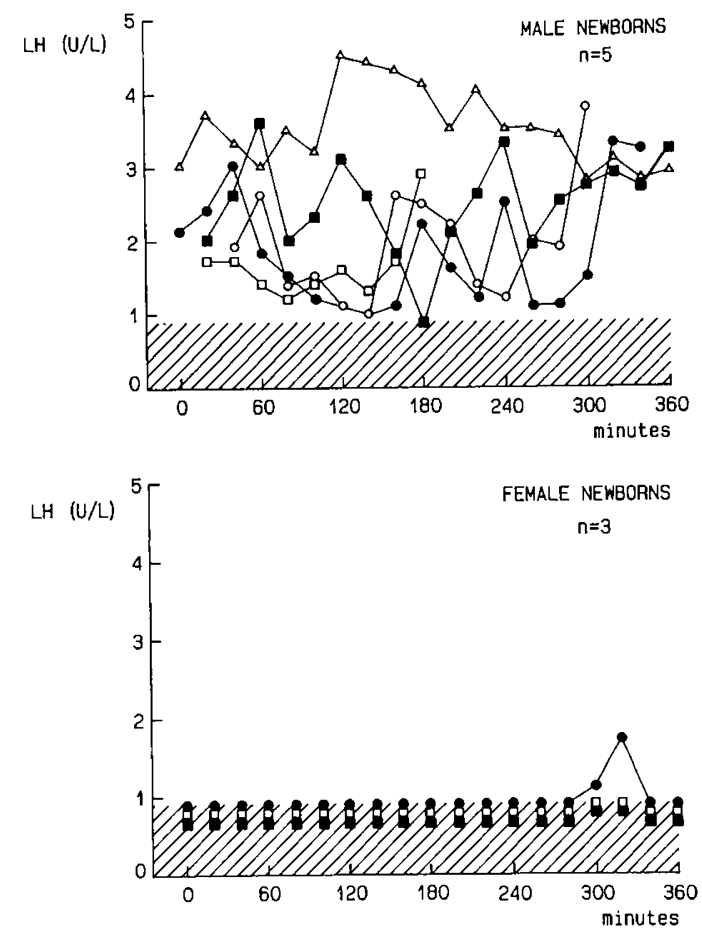

Fig. 1. Serum LH profiles in male newborns (top panel) and female newborns (bottom panel). Identical, interconnected symbols identify the sequential LH levels of individual infants. The hatched area indicates the assay detection limit.

$0.11-0.81 \mathrm{U} / \mathrm{L} / \mathrm{min}$ ). The median mass of $\mathrm{LH}$ secreted (i.e. the amount of LH discharged per unit distribution volume) per burst was $1.9 \mathrm{U} / \mathrm{L}$ (range 1.6-2.7 U/L).

The results of the testosterone, estradiol, and FSH measurements in the pooled samples of each infant are summarized in Table 1. The mean serum testosterone concentration in the male newborns was 10 -fold higher than in the female newborns. Estradiol levels were similar in male and female neonates. FSH was detectable in none of the pooled serum samples, except in that of one male.

\section{DISCUSSION}

The results suggest that the serum profile of $\mathrm{LH}$ is pulsatile and sexually differentiated in the human newborn on the day of birth.

The presented sexual dimorphism of the neonatal serum $\mathrm{LH}$ profiles in the human newborn complements the LH data obtained in the neonatal rhesus monkey $(7,8)$ and is consistent with the current knowledge on the ontogeny of LH secretion in

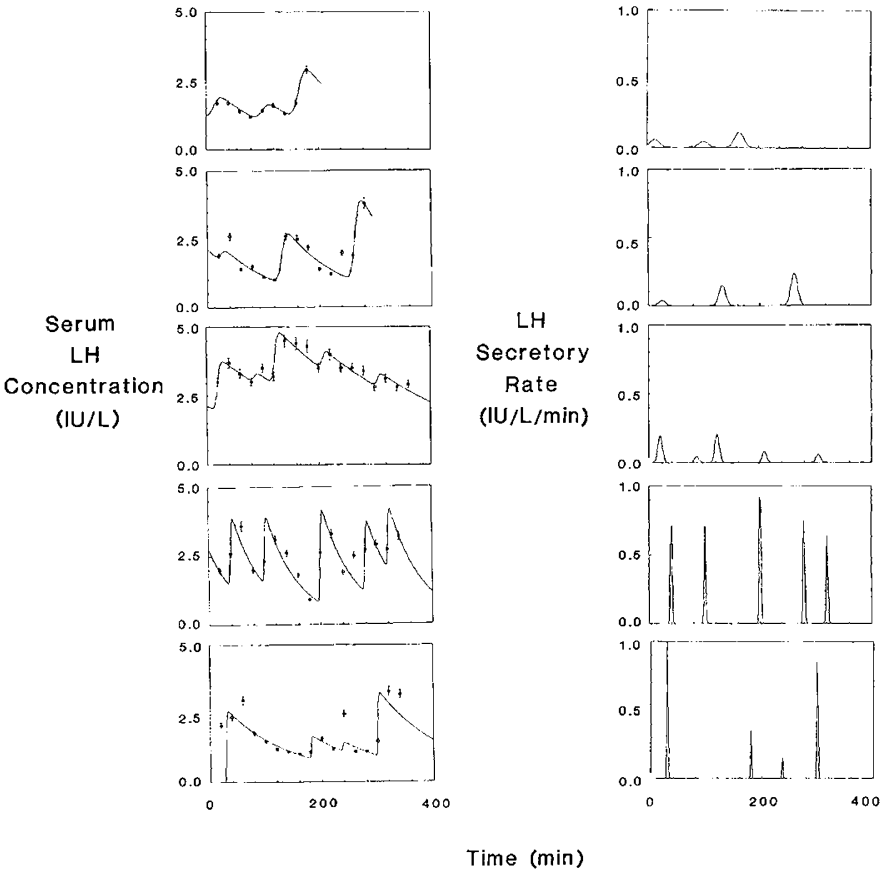

Fig. 2. Deconvolution analysis of serum LH profiles from five male newborns, ordered as in Table I (top to bottom). In the left panels, the curves through the sequential serum LH concentrations represent reconvolution fits, integrating $\mathrm{LH}$ secretory impulses with a biexponential $\mathrm{LH}$ clearance function. In the right panels, the calculated LH secretory rates of the convolution integrals are depicted.

the human fetus and infant: elevated serum $\mathrm{LH}$ concentrations in male infants compared with female infants have been reported at preterm and term birth $(5,9)$, at the end of the first postnatal week (10), and at the age of 1 to 2 mo $(4,10)$.

This study is the first to document the dynamics of human LH secretion as early as the first day after (premature) birth. The pulsatile character of $\mathrm{LH}$ secretion detected in the male newborns provides indirect evidence for pulsatile secretion of $\mathrm{LH}$-releasing hormone by the neonatal hypothalamus (11). This concept is supported by the presence of LH-releasing hormone in the fetal hypothalamus (reviewed in 1) and by the capacity of the fetal gonadotropes to respond to exogenous LH-releasing hormone (12). The observed pulse frequency of LH secretion in male newborns is similar to or higher than that in prepubertal boys, male adolescents, and men, even after correction for sampling interval; the calculated serum half-life of endogenous $\mathrm{LH}$ in male newborns was found to be similar to the half-life in men $(6,13-$ 18).

The serum concentrations of LH in the male newborns are 
elevated compared to the $\mathrm{LH}$ measured in cord serum at birth (5), an observation suggesting that the secretion of $\mathrm{LH}$ in the male infant is augmented shortly after birth. This amplification may be a rebound phenomenon evoked by the withdrawal of chorionic gonadotropin or sex steroids of placental origin, or due to other as yet undefined mechanisms capable of activating the hypothalamo-pituitary axis at this age.

Our data confirm that the male newborn produces a brisk increase in serum testosterone levels on the day of birth, in spite of a decreasing availability of chorionic gonadotropin $(3,9)$. It is conceivable that the neonatal activation of testosterone secretion, presumably by the testis, is elicited by the postnatal rise in circulating $\mathrm{LH}$ concentrations. However, we cannot exclude the possibility that the withdrawal of placental sex steroids also exerts a disinhibiting effect on testosterone release.

In conclusion, we have detected a marked, dynamic, sexual dimorphism in the neuroendocrine activity of the human gonadotropic axis on the first day of postnatal life. This finding implies that at least one neuroendocrine function in the human newborn is sexually dimorphic within hours after birth. Future research will be needed to establish whether the mechanisms underlying this sexual dimorphism are already activated early in gestation and whether they originate in the pituitary gland, the hypothalamus, or at other levels in the CNS.

\section{REFERENCES}

1. Grumbach MM, Kaplan SL 1990 The neuroendocrinology of human puberty: an ontogenetic perspective. In: Grumbach MM, Sizonenko PC, Aubert ML (eds) Control of the Onset of Puberty. Williams \& Wilkins, Baltimore, pp $1-68$

2. Kaplan SL, Grumbach MM 1976 The ontogenesis of human foetal hormones. II. Luteinizing hormone ( $\mathrm{LH}$ ) and follicle stimulating hormone (FSH). Acta Endocrinol (Copenh) 81:808-829

3. Forest MG, Cathiard AM 1975 Pattern of plasma testosterone and delta 4 androstenedione in normal newborns: evidence for testicular activity at birth. J Clin Endocrinol Metab 41:977-980

4. Waldhauser F, Weisenbacher G, Frisch H, Pollak A 1981 Pulsatile secretion of gonadotropins in early infancy. Eur J Pediatr 137:71-74

5. Massa G, de Zegher F, Vanderschueren-Lodeweyckx M 1992 Serum levels of immunoreactive inhibin, FSH and $\mathrm{LH}$ in human infants at preterm and term birth. Biol Neonate 61:150-155

6. Veldhuis JD, Carlson ML, Johnson ML 1987 The pituitary gland secretes in bursts: appraising the nature of glandular secretory impulses by simultaneous multiple-parameter deconvolution of plasma hormone concentrations. Proc Natl Acad Sci USA 84:7686-7690

7. Plant TM 1982 Pulsatile luteinizing hormone secretion in the neonatal male rhesus monkey. J Endocrinol 93:71-74

8. Plant TM 1986 A striking sex difference in the gonadotropin response to gonadectomy during infantile development in the rhesus monkey. Endocrinology 119:539-545

9. Corbier P, Dehennin L, Castanier M, Mebazaa A, Edwards DA, Roffi J 1990 Sex differences in serum luteinizing hormone and testosterone in the human neonate during the first few hours after birth. J Clin Endocrinol Metab 71:1344-1348

10. Winter JSD, Faiman C, Hobson WC, Prasad AV, Reyes FI 1975 Pituitarygonadal relations in infancy. I. Patterns of serum gonadotropin concentrations from birth to four years of age in man and chimpanzee. J Clin Endocrinol Metab 40:545-551

11. Belchetz PE, Plant TM, Nakai Y, Keogh EJ, Knobil E 1978 Hypophysial responses to continuous and intermittent delivery of hypothalamic gonadotropin releasing hormone. Science 202:631-633

12. Takagi S, Yoshida T, Tsubuta K, Ozaki H, Fujii TK, Nomura Y, Sawada M 1977 Sex differences in fetal gonadotropins and androgens. J Steroid Biochem 8:609-620

13. Dunkel L, Alfthan H, Stenman U, Selstam G, Rosberg S, Albertsson-Wikland K 1992 Developmental changes in 24-hour profiles of luteinizing hormone and follicle stimulating hormone from prepuberty to midstages of puberty in boys. J Clin Endocrinol Metab 74:890-897

14. Jakacki RI, Kelch RP, Sauder SE, Lloyd JS, Hopwood NJ, Marshall JC 1982 Pulsatile secretion of luteinizing hormone in children. J Clin Endocrinol Metab 55:453-458

15. Wu FCW, Butler GE, Kelnar CJH, Sellar RE 1990 Patterns of pulsatile luteinizing hormone secretion before and during the onset of puberty in boys: a study using an immunoradiometric assay. J Clin Endocrinol Metab 70:629-637

16. Veldhuis JD, Guardabasso V, Rogol AD, Evans WS, Oerter K, Johnson ML Rodbard D 1987 Appraising the nature of luteinizing hormone secretory events in man. Am J Physiol 252:E599-E605

17. Veldhuis JD, Johnson ML 1988 In vivo dynamics of luteinizing hormone secretion and clearance in man: assessment by deconvolution mechanics. $J$ Clin Endocrinol Metab 66:1291-1300

18. Veldhuis JD, Johnson ML, Dufau ML 1989 Physiological attributes of endogenous bioactive luteinizing hormone secretory bursts in man: Assessment of deconvolution analysis and in vitro bioassay of LH. Am J Physiol 256:E199E207 